\title{
To fix or not to fix?
}

Jonathan is a 9-year-old boy and has a complete transverse midshaft slightly displaced both bone forearm fracture. In the emergency department, the decision was made to treat him conservatively with a long-arm cast. The parents found another solution on the Internet: elastic stable intramedullary nails (ESIN). They read that the ESIN might improve Jonathan's outcome, avoid secondary displacement, and allow faster recovery with minimal morbidity. They ask for your advice.

What would you say to these parents and child? Are you going to measure the "slight" angulation to decide whether to immobilize or reduce and fix? Is ESIN your number one and only solution for a potentially unstable diaphyseal forearm fracture? Is your emergency team skilled enough for adequate well-molded long-arm casting? Have you had a litigation about cast issues in the past? Are you going to consider the parents' and child's request for early mobilization in your decision process? Are you going to remove the nails if you fix the bone? Etc., etc., ...

In the era of expert opinion, evidence-based medicine, and free access to information, Jonathan and his parents deserve a well-balanced expert answer to their question. In our demanding and fast-transforming society, the immediate perfect result with minimal burden is what they expect.

Questioning the dogma in pediatric orthopedics is imperative. Challenging knowledge by taking into account new techniques and materials is part of the process. As doctors, we pledge to provide the best care to our patients. We also have financial pressures from both institutions and insurance companies. Legal issues may affect our decision-making process. Our personal experience with casts and hardware will impact our final management plan. All these items have to be weighted up, evaluated, and pondered in our mind to come out with the best answer for Jonathan's parents.

The question "To fix or not to fix" frequently rises in a trauma surgeon's decision-making process. It may sound like a trivial question: on the contrary ... and far from it. Nissen was a renowned German surgeon who operated on A. Einstein. ${ }^{[1]}$ He was head of surgery in the University Hospital of Basel in Switzerland. The gastric fundoplication he described in 1956 still carries his name. According to him, "It takes 5 years to learn a surgical technique, 10 years to master the indications and a surgeon's life to know when NOT to operate." This is in total agreement with the current principles of fractures' management in children.

The trend for surgical fixation of pediatric fractures is a fact, affecting clavicle, humerus (supracondylar fracture), as well as the femur and tibia. ${ }^{[2-4]}$ This trend is noticeable to every pediatric orthopedic surgeon with some gray hair or more than 20 years of experience. Fixing has become the way to go. It has become a common practice nowadays that articles on the art of conservative management started to be published. ${ }^{[5]}$

Well-conducted adult randomized clinical trials on clavicle fractures have prompted a shift toward surgery. Adult orthopedic surgeons frequently challenge the conservative treatment of a clavicle fracture in children. Most of our young colleagues in training have significant experience of adult trauma surgery. They will promote the advantages of clavicle plating and challenge the dogma "Clavicle fracture = arm sling," especially in adolescents. The task of the trainer is to remind these future surgeons of the remodeling potentials of a growing child, as well as the lack of scientific evidence for plating in the pediatric population, including the adolescent.

In pediatric fracture management, an excellent knowledge of remodeling is necessary. The growing skeleton has a great ability for fast healing and significant remodeling. A vast amount of literature is available on this subject, including useful reference publications. ${ }^{[6]}$ Nevertheless, even among experts, disagreement often occurs on the amount of angular deformity that will remodel.

An adequate casting technique requires skills, experience, and practice. Residents in training have limited working hours but unlimited eagerness to operate. They want to fix and gain surgical experience. With the increase in the surgical management of fractures in children, their exposure to conservative measures such as casting and wedging is declining. The art of casting is disappearing. Molding wet plaster of Paris on an adequately positioned forearm is a rare encounter in Switzerland. It takes time and diligence. We do not have time anymore. Maybe, we do not take it! Applying fast-hardening nonmoldable synthetic plaster material is a commonplace. With our overdemanding youth clientele, the challenge in synthetic casting is choosing the right color! Waterproof protection allowing swimming during summer holidays has become part of the deal. However, the molding, gentle constant traction, full supination in case of dorsal apex angulation, and adequate plaster construction should remain. Many informative videos are available on the Internet, with significant variation in quality. ${ }^{[7]}$ There are very few countries where casting nurses or paramedics have recognized titles and qualifications. Most train on the spot and gain experience while practicing.

Most litigation related to casting has reported poor application and inadequate removal technique. Over the past 20 years, the rise in negligence claims in the UK greatly affected the decision-making process of young pediatric orthopedic surgeons. ${ }^{[8]}$ Why use a cast when you can fix? 
Maitezeau described the surgical technique for ESIN in the forearm as one of the most demanding among all flexible intramedullary nailings. ${ }^{[9]}$ Experience through repeated exposure is, therefore, necessary but becomes a challenge when residents have restricted hours and are heavily burdened with administrative constrains. Flexible intramedullary nailing in the forearm is not complication free. Whoever wants to fix Jonathan's fracture should totally master the technique and have been well taught. In our institutions, similar numbers of radiographs, outpatient clinic appointments, and complications (although different) were found when comparing ESIN and casting in displaced pediatric forearm fractures. ${ }^{[10]}$ We are not there yet, with regard to financial benefit or medical advantage. The largest series to date reported $14.8 \%$ of complications, most related to the incorrect use of the technique. The authors emphasized the importance of following the right indication, paying attention to biochemical principles and applying the correct surgical technique. ${ }^{[11]}$

More and more evidence-based pediatric orthopedic trauma guidelines and standards are available, although often based on expert opinions more than randomized studies. ${ }^{[12,13]}$ The scientific evidence is still scarce. For example, the question to fix or not to fix long bone diaphyseal fractures remains, especially regarding the femur in preschool children and the tibia, whatever the age. The emergence and use of patient-related outcome measures (PROMs) are welcomed. ${ }^{[14]}$ PROMs will most likely help a great deal in assessing our daily practice with more objectivity.

Following a fracture, demanding parents may no longer accept results that are anything less than excellent. Applied to fracture management, the word "acceptable" has changed to "perfect." Access to adequate information about the surgical care of pediatric fractures is free and available to all. The expectation of informed parents is high and understandable. Moreover, in 2019, children with a fracture want to be back in action as quickly as possible. Are we therefore going to follow the trend and fix more?

Pediatric trauma and orthopedic surgeons have constraints and expectations. The age and condition of the child, the pattern of the fracture, the local facilities, the surgeon's knowledge and experience, financial considerations as well as parental expectations finely tune the balance between surgery and conservative treatment. It is like a recipe where the cook has to be in good health, familiar with all ingredients, know the available cooking techniques, master his kitchen hardware, and be familiar with his guests' expectations to offer the perfect meal. The question "to fix or not to fix" is always part of my assessment process with pediatric fractures ... but I do not always have a straightforward answer.

\section{Nicolas Lutz}

Department of Pediatric Surgery, University Hospital of Lausanne, Lausanne, Switzerland
Address for correspondence: Dr. Nicolas Lutz,

University Hospital of Lausanne, Rue du Bugnon, CH-1010 Lausanne, Switzerland.

E-mail: nicolas.lutz@chuv.ch

\section{REFERENCES}

1. Nissen R. Available from: https://en.wikipedia.org/wiki/Rudolph Nissen. [Last accessed on 2019 Jun 15].

2. Kosuge D, Barry M. Changing trends in the management of children's fractures. Bone Joint J 2015;97-B: 442-8.

3. Helenius I, Lamberg TS, Kääriäinen S, Impinen A, Pakarinen MP. Operative treatment of fractures in children is increasing. A population-based study from Finland. J Bone Joint Surg Am 2009;91:2612-6.

4. Sinikumpu JJ, Lautamo A, Pokka T, Serlo W. The increasing incidence of paediatric diaphyseal both-bone forearm fractures and their internal fixation during the last decade. Injury 2012;43:362-6.

5. Bryson DJ, Shivji FS, Price KR, Lawniczak D, Chell J and Hunter JB. The lost art of conservative management of paediatric fractures. Bone Joint $^{360}$ 2016;5:1. Available from: https://online.boneandjoint.org.uk/ doi/abs/10.1302/2048-0105.51.360403. [Last accessed on 2019 Jun 15].

6. Wilkins KE. Principles of fracture remodeling in children. Injury 2005;36 Suppl 1:A3-11.

7. Forearm fracture reduction. Available from: https://www.youtube.com/ watch? $\mathrm{v}=\mathrm{gQDebkQEmUE}$. [Last accessed on 2019 Jun 15].

8. A'Court J, Yassa R, Charalambous CP. Litigation related to casting in orthopaedics-an analysis of claims against the national health service in England. Injury 2017;48:1405-7.

9. Metaizeau JP. Ostheosynthèse Chez L'enfant. Montpellier, France: Sauramps Medical editions; 1988. p. 11.

10. Leuba A, Ceroni D, Tabard A, Tercier S, Bregou A, Zambelli PY, et al. Flexible Intramedullary Nailing in Pediatric Forearm Fractures: There is Still Place for Improvement. Oral Presentation, EPOS Annual Meeting. Oslo, Norway; 2018.

11. Fernandez FF, Langendörfer M, Wirth T, Eberhardt O. Failures and complications in intramedullary nailing of children's forearm fractures. J Child Orthop 2010;4:159-67.

12. AAOS Guideline for the Treatment of Pediatric Supracondylar Humerus Fracture. Available from: http://www.orthoguidelines.org/ topic?id=1010. [Last accessed on 2019 Jun 15].

13. BOAST - Supracondylar Fractures in the Humerus in Children. Available from: https://www.boa.ac.uk/resources/knowledge-hub/boast -11-pdf.html. [Last accessed on 2019 Jun 15].

14. Narayanan U, Patel S, Propp R, Ferkul A, Camp M, Murphy A. Development and Content Validation of the Patient-Reported Outcomes of Fracture Healing. Oral Presentation at EPOS Annual Meeting. Tel Haviv, Israel; 2019.

This is an open access journal, and articles are distributed under the terms of the Creative Commons Attribution-NonCommercial-ShareAlike 4.0 License, which allows others to remix, tweak, and build upon the work non-commercially, as long as appropriate credit is given and the new creations are licensed under the identical terms.

\begin{tabular}{|l|l|}
\hline \multicolumn{3}{|c|}{ Access this article online } \\
\hline Quick Response Code: & Website: \\
\hline
\end{tabular}

How to cite this article: Lutz N. To fix or not to fix? J Musculoskelet Surg Res 2019;3:317-8. 